\title{
Structural Analysis of Some Alkali Diborate Glasses
}

\author{
Y.B. SAddeEk ${ }^{a}$, M.S. GAAfar ${ }^{b, *}$, N.S. AbD El-Aal ${ }^{b}$ And L. Abd El-LatiF ${ }^{b}$ \\ ${ }^{a}$ Physics Department, Faculty of Science, Al-Azhar University, P.O. 71452, Assiut, Egypt \\ ${ }^{b}$ Ultrasonic Laboratory, National Institute for Standards \\ Tersa Str., P.O. Box 136, El-Haram, El-Giza 12211, Egypt
}

(Received January 30, 2009; in final form March 24, 2009)

\begin{abstract}
This manuscript presents a theoretical analysis of the correlation between the computed bulk modulus and the structure of a series of multicomponent sodium diborate based glasses in terms of the bond compression model. The main parameters in the analysis were the computed elastic moduli, the average stretching force constant and the average atomic ring size. These parameters were calculated for every glass series and for every glass composition. The results showed that the average force constant and the elastic moduli of these glasses are sensitive to the decrease in the sodium diborate content. This behaviour was attributed to the increase in the molar volume, and to the role of the different modifiers.
\end{abstract}

PACS numbers: 61.43.Fs, 62.30. $+\mathrm{d}, 65.60 .+\mathrm{a}$

\section{Introduction}

The boron atom in borate crystals and glasses is usually coordinated with either three or four oxygen atoms forming $\left[\mathrm{BO}_{3}\right]$ or $\left[\mathrm{BO}_{4}\right]$ structural units. These two fundamental units can be arbitrarily combined to form either the so-called super-structure or different $\mathrm{B}_{x} \mathrm{O}_{y}$ structural groups like boroxol ring, pentaborate, tetraborate, diborate groups etc. In the alkali borate glass systems, each alkali oxide is associated with a proportional quantity of $\mathrm{B}_{2} \mathrm{O}_{3}$; so that, the number of the structural units depends on both the nature and the total concentration of the added modifiers, and can often give rise to tightly organized structures resulting in intermediate order [1-5]. In sodium borate glasses there are three types of structural groupings; namely boroxol rings, tetraborate units and diborate units. All of these groups share two distinct types of boron configurations; $\mathrm{BO}_{3}$ triangles and $\mathrm{BO}_{4}$ tetrahedra with bridging oxygen ions for each type. In high-sodium borate glasses (between 20 and $30 \mathrm{~mol} \%$ of $\mathrm{Na}_{2} \mathrm{O}$ ), tetraborate groups are partially rearranged, and one $\mathrm{Na}_{2} \mathrm{O}$ forms two diborate units at the expense of a tetraborate unit, with $\mathrm{BO}_{4} /\left(\mathrm{BO}_{3}+\mathrm{BO}_{4}\right)=0.5$. As a result, one $\mathrm{Na}_{2} \mathrm{O}$ forms two $\mathrm{BO}_{4}$ units, which makes the network structure three-dimensional [6-9]. Kodama [5] analyzed the elastic properties of sodium borate glasses in terms of three structural units defined as $\mathrm{B}_{3} \equiv a$, $\mathrm{M}^{+} \mathrm{B}_{2} \mathrm{O}^{-} \equiv b$ and $\mathrm{M}^{+} \mathrm{B}_{4}^{-} \equiv c$, where represents a bridging oxygen and $\mathrm{O}^{-}$is a non-bridging oxygen. It is assumed that these structural units have their respective elastic constants defined on the basis of a thermodynamic

* corresponding author; e-mail: mohamed_s_gaafar@hotmail.com equation of deformed body, so the rigidity of the glass will increase with the structural unit $c$ and decreases with the structural unit $b$. They found that the sound velocity in the sodium-borate glasses shows a single maximum (around $x=0.34 \mathrm{~mol} . \%$ ) correlated with the increase in the number of non-bridging oxygens. On the other hand, the $\mathrm{MoO}_{3}, \mathrm{Nb}_{2} \mathrm{O}_{5}, \mathrm{PbO}$, and $\mathrm{Bi}_{2} \mathrm{O}_{3}$ oxides appeared as non-conventional network formers because of the participation of $\mathrm{MoO}_{4}, \mathrm{MoO}_{6}, \mathrm{NbO}_{4}, \mathrm{PbO}_{4}$, and $\mathrm{BiO}_{6}$ groups in the formation of the glass network.

Therefore, the analytical structural study of the borate-based glasses correlated with their macroscopic properties presents a challenge in the field of condensed matter physics and chemistry. This correlation helps in the design of materials suitable for specific applications. These glasses are commonly used in the field of opto-acoustical electronics, piezoelectric actuator, and in nonlinear devices for frequency conversion in the ultraviolet region. Meanwhile, these glasses and their crystalline counterparts are considered to be good candidates for the optically induced elastoopticity $[10,11]$. Also, a series of multi-component non-conventional glasses with interesting properties, e.g. low dielectric constant, relatively low dielectric loss, and good radiation shielding for $\gamma$-rays can be synthesized [12-15]. These glasses exhibit a high refractive index, widely adjustable in the range from 1.8 to 2.5 by the appropriate glass composition and have high energy gap attributable to the high polarizability of $\mathrm{Bi}_{2} \mathrm{O}_{3}$ which allows using them in wide spectra range from UV up to infrared $[16,17]$.

Inspection of the microstructure and the mechanical properties of the borate glasses were interpreted in terms of collected qualitative or quantitative data from various kinds of characterization techniques. The rigidity 
and the elastic properties of these glasses are very informative about its structure. One way to determine the rigidity is the determination of the sizes of the borate rings, which in turn are influenced by the chemical nature of the modifying oxide. Therefore, the purpose of the present work is to deduce the structural changes of the sodium diborate based glasses upon its modification by non-conditional glass formers like $\mathrm{PbO}$, and $\mathrm{Bi}_{2} \mathrm{O}_{3}$, $\mathrm{MoO}_{3}$, and $\mathrm{Nb}_{2} \mathrm{O}_{5}$. The computation of the elastic moduli based on the data given by Saddeek et al. [18-20] has been calculated in terms of the bond-compression model proposed by Bridge et al. [21].

\section{Theoretical analysis}

The structure of oxide glasses can be described in terms of the bond compression model which was first introduced by Bridge et al. [21] for the study of single-component glass, was later developed for multicomponent glasses [22]. The model is based on the observation that the measured bulk modulus $K_{\mathrm{e}}$ of oxide glasses is always markedly smaller than $K_{\mathrm{bc}}$, the bulk modulus calculated under the assumption that each covalent bond experiences the linear contraction of the whole sample. Obviously, a sizable part of the volume change is due to a distortion of the network. In order to quantify the treatment of this effect, the model makes several assumptions:

(i) The elastic moduli only depend on the "connectivity" of the network (number of bonds per cation) and on the average force constant. The calculated bulk modulus $\left(K_{\mathrm{bc}}\right)$ according to this model and the bond stretching-force constant $f$ can be estimated according to the relations

$$
\begin{aligned}
& K_{\mathrm{bc}}=\frac{\sum_{i} x_{i} n_{\mathrm{b}} r_{\mathrm{a}}^{2} f}{9} \quad[\mathrm{GPa}], \\
& f=5.28 N\left(\frac{X_{\mathrm{a}} X_{\mathrm{b}}}{r_{\mathrm{a}}^{2}}\right)^{3 / 4}+30 \quad\left[\mathrm{~N} \mathrm{~m}^{-1}\right],
\end{aligned}
$$

where $x$ is the mole fraction of the component oxide, $n_{\mathrm{b}}$ is the number of network bonds per unit volume, $r_{\mathrm{a}}(\mathrm{nm})$ is the bond length, $N$ is the bond order $(1,2$, or 3$), X_{\mathrm{a}}$ and $X_{\mathrm{b}}$ are the electronegativities of the anion and the cation, respectively.

(ii) The ratio between the calculated elastic moduli and the experimental one $\left(K_{\mathrm{bc}} / K_{\mathrm{e}}\right)$ is assumed to be directly proportional to the atomic ring size $(l)$. The atomic ring size is defined as the ring perimeter (number of bonds times bond length divided by $\pi$ ), and is given by the relation

$$
l=\left(0.0106 \frac{f}{K_{\mathrm{e}}}\right)^{0.26} \quad[\mathrm{~nm}],
$$

where $K_{\mathrm{e}}$ is the experimental bulk modulus. Therefore, a value of $K_{\mathrm{bc}} / K_{\mathrm{e}} \gg 1$ indicates a relatively open (i.e. large ringed) three-dimensional network with ring size tending to increase with $K_{\mathrm{bc}} / K_{\mathrm{e}}$ and network bond bending (non-network compression) processes predominate when the glasses are subjected to bulk compression. The authors found that the values of $K_{\mathrm{bc}} / K_{\mathrm{e}}$ are 3.05, 3.08,
4.39 and 6.62 for pure $\mathrm{SiO}_{2}, \mathrm{P}_{2} \mathrm{O}_{5}, \mathrm{GeO}_{2}$ and $\mathrm{As}_{2} \mathrm{O}_{3}$ glasses, respectively, and the conformable atomic ring size of these glasses is $0.58,0.567,0.631$ and $0.722 \mathrm{~nm}$, respectively [21].

Moreover, Poisson's ratio $\sigma_{\text {cal }}$ was given according to this model as

$$
\begin{aligned}
& \sigma_{\text {cal }}=0.28\left(\overline{n_{\mathrm{c}}}\right)^{-1 / 4}, \\
& \overline{n_{\mathrm{c}}}=\left(\frac{1}{\eta}\right) \sum_{i} x_{i}\left(n_{\mathrm{c}}\right)_{i}\left(N_{\mathrm{c}}\right)_{i},
\end{aligned}
$$

where $\overline{n_{\mathrm{c}}}$ is the average cross-link density, $n_{\mathrm{c}}$ is the number of cross-links per unit cation which equals the number of bonds minus $2, N_{\mathrm{c}}$ is the number of cations per unit glass formula unit and $\eta$ is the total number of cations per unit glass formula unit given by $\eta=\sum_{i} x_{i}\left(N_{\mathrm{c}}\right)_{i}$. The model [21] proposes that for tensile stresses, applied parallel to the chains, the longitudinal strain produced will be the same for all three networks i.e. it is unaffected by the cross links. The ratio of lateral to longitudinal strain $(\sigma)$ increases with decreasing cross-link density.

\section{Results and discussion}

The quantitative analysis of the literature data [18-20] in terms of the bond compression model was done using the set of parameters listed in Table I. The set was

TABLE I

The coordination number $(N)$, the cation-anion bond length $\left(r_{\mathrm{a}}\right)$, the first order stretching force constant $(f)$, and the electronegativity of the cation $\left(X_{\mathrm{a}}\right)$, of the oxides included in this study.

\begin{tabular}{c|c|c|c|c}
\hline \hline Oxide & $N$ & $r_{\mathrm{a}}[\mathrm{nm}]$ & $f\left[\mathrm{~N} \mathrm{~m}^{-1}\right]$ & $X_{\mathrm{a}}$ \\
\hline $\mathrm{B}_{2} \mathrm{O}_{3}$ & 3 & 0.1365 & 450.65 & 2 \\
$\mathrm{Na}_{2} \mathrm{O}$ & 4 & 0.196 & 145.58 & 0.93 \\
$\mathrm{Bi}_{2} \mathrm{O}_{3}$ & 6 & 0.240 & 192.24 & 2.02 \\
$\mathrm{MoO}_{3}$ & 6 & 0.196 & 273.9 & 2.16 \\
$\mathrm{Nb}_{2} \mathrm{O}_{5}$ & 6,4 & 0.170 & 270.74 & 1.6 \\
$\mathrm{PbO}$ & 4 & 0.214 & 257.43 & 2.33 \\
\hline
\end{tabular}

Values of the coordination number, the bond length, the electronegativity of the cation were taken from Refs. [23, 25].

adapted to the crystal structure of each oxide of the studied glass series [23]. These parameters are used in calculating the average stretching force constant $F$, the number of network bonds per unit volume $n_{\mathrm{b}}$, the bulk modulus $K_{\mathrm{bc}}$, the average atomic ring size $l$, and the ratio $K_{\mathrm{bc}} / K_{\mathrm{e}}$. In Table I, one has two entries for the coordination number of $\mathrm{Nb}_{2} \mathrm{O}_{5}, \mathrm{~N}=6$ and $\mathrm{N}=4$. Here we follow the work of Mohan et al. [24], which showed that the niobium can be coordinated with either four or six oxygen atoms, depending on the atomic composition. The bond density in Table II was calculated according to their rules. 
TABLE II

The number of network bonds per unit volume $\left(n_{\mathrm{b}}\right)$, the average cross-link density $\left(\overline{n_{\mathrm{c}}}\right)$, the experimentally determined bulk modulus $\left(K_{\mathrm{e}}\right)$, the bond compression bulk modulus $\left(K_{\mathrm{bc}}\right)$, the ratio $\left(K_{\mathrm{bc}} / K_{\mathrm{e}}\right)$, the average force constant $(f)$, the average ring diameter $(l)$ of the sodium diborate glasses.

\begin{tabular}{|c|c|c|c|c|c|c|c|c|c|c|c|c|c|c|}
\hline \multicolumn{7}{|c|}{ Composition in [mol\%] } & \multirow{2}{*}{$\begin{array}{c}n_{\mathrm{b}} \times 10^{28} \\
{\left[\mathrm{~m}^{-3}\right]}\end{array}$} & \multirow[t]{2}{*}{$\overline{n_{\mathrm{c}}}$} & \multirow{2}{*}{$\begin{array}{c}K_{\mathrm{e}} \\
{[\mathrm{GPa}]}\end{array}$} & \multirow{2}{*}{$\begin{array}{c}K_{\mathrm{bc}} \\
{[\mathrm{GPa}]}\end{array}$} & \multirow[t]{2}{*}{$\sigma$} & \multirow{2}{*}{$K_{\mathrm{bc}} / K_{\mathrm{e}}$} & \multirow{2}{*}{$\begin{array}{c}f \\
{\left[\mathrm{~N} \mathrm{~m}^{-1}\right]}\end{array}$} & \multirow{2}{*}{$\begin{array}{c}l \\
{[\mathrm{~nm}]}\end{array}$} \\
\hline $\mathrm{B}_{2} \mathrm{O}_{3}$ & $\mathrm{Na}_{2} \mathrm{O}$ & $\mathrm{Bi}_{2} \mathrm{O}_{3}$ & $\mathrm{MoO}_{3}$ & $\mathrm{Nb}_{2} \mathrm{O}_{5}$ & $\mathrm{PbO}$ & Name & & & & & & & & \\
\hline 1.000 & - & - & - & - & - & Pure boron & 4.77 & 1.000 & 13.26 & 44.76 & 0.280 & 3.38 & 450.0 & 0.766 \\
\hline 0.667 & 0.333 & - & - & - & - & NB & 9.25 & 2.332 & 45.89 & 94.64 & 0.227 & 2.06 & 309.6 & 0.503 \\
\hline 0.600 & 0.300 & - & - & - & 0.100 & $\mathrm{NBPb} 1$ & 8.93 & 2.316 & 43.99 & 93.75 & 0.227 & 2.13 & 304.7 & 0.507 \\
\hline 0.533 & 0.267 & - & - & - & 0.200 & $\mathrm{NBPb} 2$ & 8.50 & 2.298 & 40.93 & 91.62 & 0.227 & 2.24 & 299.6 & 0.514 \\
\hline 0.467 & 0.233 & - & - & - & 0.300 & $\mathrm{NBPb} 3$ & 8.08 & 2.273 & 40.16 & 89.23 & 0.228 & 2.22 & 294.8 & 0.514 \\
\hline 0.400 & 0.200 & - & - & - & 0.400 & $\mathrm{NBPb} 4$ & 7.93 & 2.250 & 39.36 & 89.81 & 0.229 & 2.28 & 289.7 & 0.515 \\
\hline 0.333 & 0.167 & - & - & - & 0.500 & NBPb5 & 7.96 & 2.224 & 38.56 & 92.38 & 0.229 & 2.40 & 284.4 & 0.515 \\
\hline 0.267 & 0.133 & - & - & - & 0.600 & NBPb6 & 7.75 & 2.189 & 36.69 & 92.17 & 0.230 & 2.51 & 279.4 & 0.519 \\
\hline 0.200 & 0.100 & - & - & - & 0.700 & $\mathrm{NBPb} 7$ & 7.44 & 2.154 & 32.00 & 90.69 & 0.231 & 2.83 & 273.9 & 0.535 \\
\hline 0.133 & 0.067 & - & - & - & 0.800 & $\mathrm{NBPb} 8$ & 7.15 & 2.113 & 28.61 & 89.25 & 0.232 & 3.12 & 268.4 & 0.548 \\
\hline 0.633 & 0.317 & 0.025 & 0.025 & - & - & NBBiMO1 & 9.10 & 2.40 & 48.10 & 95.40 & 0.225 & 1.98 & 306.7 & 0.496 \\
\hline 0.600 & 0.300 & 0.050 & 0.050 & - & - & NBBiMO2 & 8.95 & 2.46 & 48.40 & 95.89 & 0.224 & 1.98 & 303.9 & 0.494 \\
\hline 0.567 & 0.283 & 0.075 & 0.075 & - & - & NBBiMO3 & 8.59 & 2.53 & 49.30 & 93.99 & 0.222 & 1.91 & 301.1 & 0.490 \\
\hline 0.533 & 0.267 & 0.010 & 0.010 & - & - & NBBiMO4 & 8.63 & 2.60 & 50.30 & 96.27 & 0.221 & 1.91 & 298.2 & 0.486 \\
\hline 0.500 & 0.250 & 0.125 & 0.125 & - & - & NBBiMO5 & 8.36 & 2.67 & 50.70 & 95.02 & 0.219 & 1.87 & 295.7 & 0.484 \\
\hline 0.467 & 0.233 & 0.150 & 0.150 & - & - & NBBiMO6 & 8.26 & 2.74 & 51.00 & 95.49 & 0.218 & 1.87 & 293.2 & 0.483 \\
\hline 0.433 & 0.217 & 0.175 & 0.175 & - & - & NBBiMO7 & 8.12 & 2.81 & 51.10 & 95.40 & 0.216 & 1.87 & 290.6 & 0.481 \\
\hline 0.400 & 0.200 & 0.200 & 0.200 & - & - & NBBiMO8 & 8.13 & 2.89 & 51.80 & 97.07 & 0.215 & 1.87 & 288.3 & 0.479 \\
\hline 0.633 & 0.317 & 0.025 & - & 0.025 & - & NBBiNb1 & 8.11 & 2.42 & 43.7 & 84.65 & 0.225 & 1.94 & 304.8 & 0.507 \\
\hline 0.600 & 0.300 & 0.050 & - & 0.050 & - & NBBiNb2 & 7.38 & 2.50 & 43.3 & 78.39 & 0.223 & 1.81 & 300.2 & 0.507 \\
\hline 0.567 & 0.283 & 0.075 & - & 0.075 & - & NBBiNb3 & 6.90 & 2.58 & 41.4 & 74.40 & 0.221 & 1.80 & 295.7 & 0.511 \\
\hline 0.533 & 0.267 & 0.010 & - & 0.010 & - & NBBiNb4 & 6.60 & 2.67 & 44.2 & 72.33 & 0.219 & 1.64 & 291.1 & 0.500 \\
\hline 0.500 & 0.250 & 0.125 & - & 0.125 & - & NBBiNb5 & 6.25 & 2.75 & 44.4 & 69.49 & 0.217 & 1.57 & 286.9 & 0.497 \\
\hline 0.467 & 0.233 & 0.150 & - & 0.150 & - & NBBiNb6 & 6.08 & 2.83 & 46.2 & 68.54 & 0.216 & 1.48 & 282.9 & 0.491 \\
\hline
\end{tabular}

The compositions of the series $\mathrm{NBPb}$ were according to [18], NBBiMO were according to [19], NBBiNb were according to [20].

The values of $n_{\mathrm{b}}, K_{\mathrm{bc}}, K_{\mathrm{bc}} / K_{\mathrm{e}}, f, l$, and $n_{\mathrm{c}}$ for pure $\mathrm{B}_{2} \mathrm{O}_{3}$ were according to [26].

The determination of the average cross-link density was based on the computation of both the coordination number of the modifiers and the former on one hand, and on the $N_{4}$, the ratio of four-to-three-coordinated boron in the borate glass, on the other hand. Also, it was found that the average force constant $(F)$ is governed by the reciprocal of the bond length. The bond lengths for $\mathrm{BO}_{3}$ and for $\mathrm{BO}_{4}$ are $0.1365 \mathrm{~nm}$ and $0.1475 \mathrm{~nm}$, respectively. Thus, according to the results of the model, the structure of the stoichiometry sodium diborate glass is more rigid than that of the pure vitreous $\mathrm{B}_{2} \mathrm{O}_{3}$. The latter is less cross-linked, has a large ring and high $K_{\mathrm{bc}} / K_{\mathrm{e}}$ value than those of the former. Previously [21] it has been argued that the high value of the ratio $K_{\mathrm{bc}} / K_{\mathrm{e}}$ more than 3 indicates that network bond bending (or non-network bond compression) processes predominate when these materials are subjected to bulk compression. The rigidity of the stoichiometry sodium diborate glass network is maximized according to some former studies [5, 26]. Thus, analysis of the computed elastic moduli according to the bond-compression model may be achieved of these glass series [18-20] as follows.

\section{1. $\mathrm{NBPb}$ series}

Modification of the sodium diborate glasses with $\mathrm{PbO}$ having 4 coordination number and $0.214 \mathrm{~nm}$ bond length results in an increase in the molar volume [18], decrease in the number of bonds per unit volume $\left(n_{\mathrm{b}}\right)$ and a decrease in the cross-links (Fig. 1) in the glass system with decreasing the sodium diborate content. The decrease in $n_{\mathrm{b}}$ and the average cross-link density is attributed to both the decrease in the total number of cations per unit glass formula unit $[21,22]$ and the increase in molar volume confirming the creation of non-bridging oxygens NBOs as the oxygen molar volume $\left(V_{\mathrm{O}}\right)$ increases from $12.8 \times 10^{-6}$ to $26.9 \times 10^{-6} \mathrm{~m}^{3} / \mathrm{mol}$ [18] with the increase of $\mathrm{PbO}$ content which expands (opens up) the structure of the tightly network of $\mathrm{Na}_{2} \mathrm{~B}_{4} \mathrm{O}_{7}(\mathrm{NBO})$ glass. Therefore, the number of network bonds per unit volume will decrease (Fig. 2) from $9.25 \times 10^{28}$ to $7.15 \times 10^{28} \mathrm{~m}^{3}$. According to Table II, the $K_{\mathrm{bc}}$ (Fig. 3) decreases, the packing density, and the experimentally determined bulk modulus $K_{\mathrm{e}}$ [18] decrease as the sodium diborate content decreases. Thus, the structure will be less linked and the network of these glasses becomes weaker as the average bond stretching 


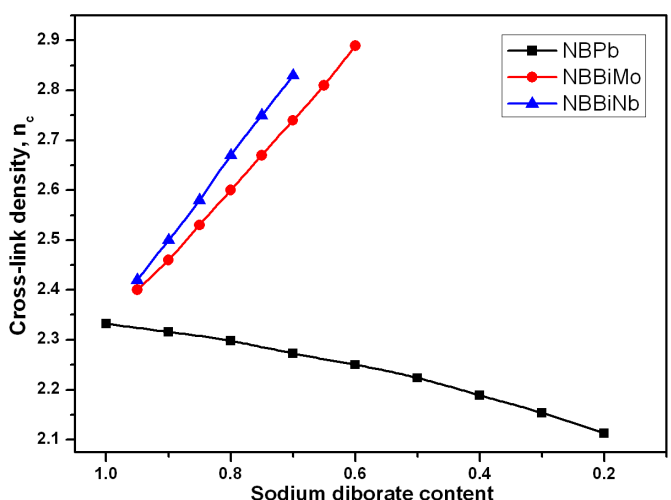

Fig. 1. The compositional dependence of the cross-link density on the sodium diborate content.

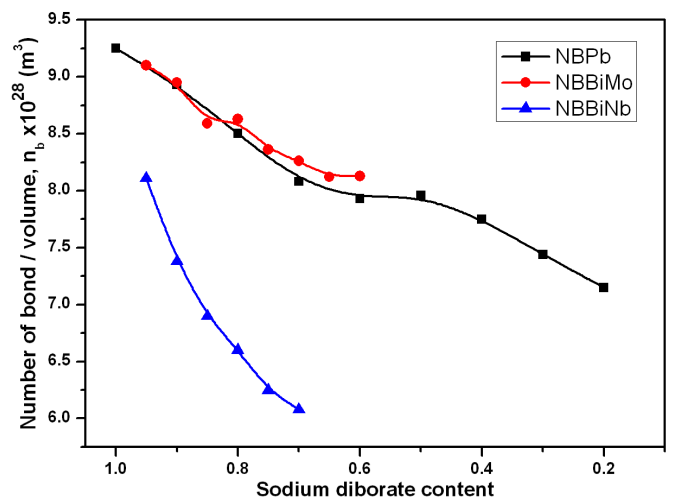

Fig. 2. The compositional dependence of the number of bonds per unit volume on the sodium diborate content.

force constant $F$ decreased (see Table II), and as a direct result the average atomic ring diameter (Fig. 4) increases which correlates with the increase in both molar volume (i.e. inter-atomic spacing) and NBOs. The suggestion by Bridge et al. [21] that the ratio $K_{\mathrm{bc}} / K_{\mathrm{e}}$ (Fig. 5) is related to the average size of the rings may be accepted in fully

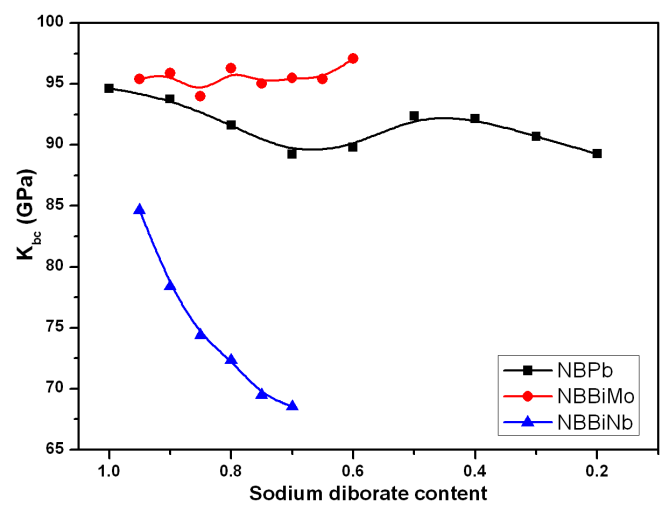

Fig. 3. The compositional dependence of computed bulk modulus on the sodium diborate content.

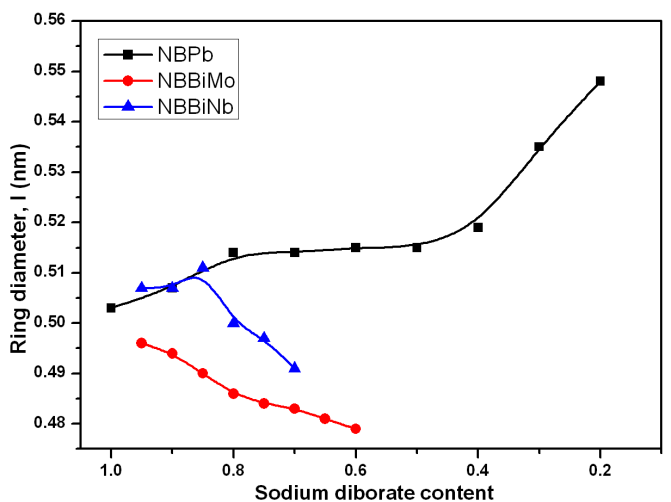

Fig. 4. The compositional dependence of the ring diameter on the sodium diborate content.

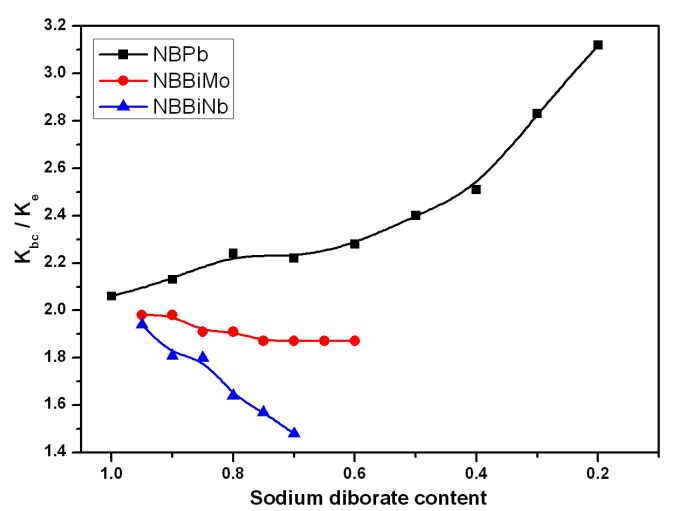

Fig. 5. The compositional dependence of the ratio $K_{\mathrm{bc}} / K_{\mathrm{e}}$ on the sodium diborate content.

polymerized glasses such as borate glasses, so the relation between $K_{\mathrm{bc}} / K_{\mathrm{e}}$ and the average ring size of this type of glasses is straightforward. The computed values of these parameters are in a good agreement with the values given previously by Bridge et al. [21] for pure $\mathrm{B}_{2} \mathrm{O}_{3}$. As discussed previously, as the value of the ratio $K_{\mathrm{bc}} / K_{\mathrm{e}}$ increases to more than unity, so the connections between the structural units will be weaker and the structure will become less stable. In addition, the increase in the values of Poisson's ratio as shown in Table II is mainly due to the decrease in cross-link density confirming the decrease in rigidity with addition of $\mathrm{PbO}$ at the expense of the $\mathrm{Na}_{2} \mathrm{~B}_{4} \mathrm{O}_{7}$ diborate.

\subsection{NBBiMo series}

According to Table II, the cross-link density, and the $K_{\mathrm{bc}}$ increases while the number of network bonds per unit volume, and the ring diameter decrease as the sodium diborate content decreases. Also, the molar volume increases, oxygen molar volume increases and the packing density [19] decreases of these glasses with the decrease in the sodium diborate content. The increase in the average cross-link density is attributed to the replacement of both bismuth and molybdenum ions with higher 
coordination numbers at the expense of diborate content. On the other hand, the decrease in the number of network bonds per unit volume (Fig. 2) from $9.10 \times 10^{28}$ to $8.13 \times 10^{28} \mathrm{~m}^{3}$ is attributed to the increase in molar volume and oxygen molar volume [19] which means the increase of NBOs with addition of bismuth and molybdenum oxides at the expense of $\mathrm{Na}_{2} \mathrm{~B}_{4} \mathrm{O}_{7}$ content. In this series $n_{\mathrm{c}}$ increases markedly than the latter series which may be due to the effect of the higher coordination number of $\mathrm{Bi}_{2} \mathrm{O}_{3}$ and $\mathrm{MoO}_{3}$ than $\mathrm{PbO}$. The computed values of these parameters are in a good agreement with the values given previously [21]. Incorporation of $\mathrm{Bi}_{2} \mathrm{O}_{3}$ and $\mathrm{MoO}_{3}$ in the sodium diborate glass network increases the concentration of $\mathrm{MoO}_{6}$ and $\mathrm{BiO}_{6}$ structural units, as their coordination numbers are higher than $\mathrm{B}_{2} \mathrm{O}_{3}$, and hence leads to the increase in cross-link density and consequently the increase in $K_{\mathrm{bc}}$ and $K_{\mathrm{e}}$ values as seen in Table II. Therefore, the decrease in the values of the ratio $K_{\mathrm{bc}} / K_{\mathrm{e}}$ and average ring diameter confirm the increased rigidity of these glasses. Moreover, the decrease in the values of Poisson's ratio confirms the increased rigidity and cross-link density of these glasses through the change in the type of bonds from covalence to ionic, since the replacement of $\mathrm{B}_{2} \mathrm{O}_{3}$ (with strong $\mathrm{B}-\mathrm{O}$ bonds and lower coordination number) by $\mathrm{Bi}_{2} \mathrm{O}_{3}$ and $\mathrm{MoO}_{3}$ oxides (with weaker $\mathrm{Bi}-\mathrm{O}$ and $\mathrm{Mo}-\mathrm{O}$ bonds and higher coordination numbers) would lead to the increase in the ionic cross-links (i.e. increase in rigidity) and the decrease in the average bond stretching force constant $F$ as seen in Table II. Therefore, the increase in the elastic moduli of these glasses along with the increase in molar volume indicates the change in the type of bonding [27].

\section{3. $N B B i N b$ series}

Incorporation of $\mathrm{Bi}_{2} \mathrm{O}_{3}$ and $\mathrm{Nb}_{2} \mathrm{O}_{5}$ in the sodium diborate network results in a markedly increase in the molar volume and a decrease in the packing density [20] than the two former series. This incorporation will increase the average cross-link density and causes a constancy in the total number of cations per unit glass formula unit $[21,22]$, so the number of network bonds per unit volume strongly decreases (Fig. 2) from 8.11 to $6.08 \times 10^{28} \mathrm{~m}^{3}$. In this type of glass, more polymerization will be created as the sodium diborate content decreases, and as a result both the average ring diameter and $K_{\mathrm{bc}} / K_{\mathrm{e}}$ will decrease and the relation between them is straightforward. The behaviour of the last parameters with the decrease in the sodium diborate content is attributed to the dual role of $\mathrm{Nb}_{2} \mathrm{O}_{5}$ as a modifier/former [20]. This behaviour was noticed elsewhere [28] in a theoretical analysis of low silicate content glasses and was attributed to the dual role of $\mathrm{La}_{2} \mathrm{O}_{3}$. Moreover, the decrease in the values of Poisson's ratio confirm the increased rigidity and cross-link density of these glasses through the formation of bonds with high ionic character which would lead to the increase in the ionic cross-links (i.e. increase in rigidity) and the decrease in the average bond stretching force constant $F$ as seen in Table II.
It is inferred that modification of the sodium diborate glasses (the three series) will increase the molar volume, the average cross link density and decrease the packing density, the average force constant, and the number of bonds per unit volume, while the $K_{\mathrm{bc}}$ is very sensitive to the rate of increase of the molar volume. Accordingly, the relation between the average ring diameter and $K_{\mathrm{bc}} / K_{\mathrm{e}}$ is depending on the polymerization or depolymerization of the sodium diborate network. Also, it is worth mentioning that there is an intrinsic correlation between fragility of a liquid and bulk modulus of its glass. Jiang and Dai [29] found that there is a linear correlation between the fragility and the bulk-shear modulus ratio exists strictly at either absolute zero temperature or very high frequency. Their further analyses [29] indicate that a real flow event in bulk glasses either metallic or nonmetallic is shear dominant, and fragility is in inverse proportion to shear-induced bulk dilatation.

\section{Conclusions}

The average atomic ring size and the elastic moduli can be calculated theoretically for sodium diborate based glasses from the indicative structural parameters. The theoretical bulk modulus $K_{\mathrm{bc}}$ of these glasses is governed by the forces interlocking the network, and is increased or decreased by placing transition metal ions of high or low field strengths in the interstices of the sodium diborate network. The behavior of the sodium diborate based glasses is dependent upon the kind of glass modifier. The average ring diameter of these glasses has been calculated and it has been found that is depends upon the kind of the modifier.

\section{References}

[1] J. Shelby, Introduction to Glass Science and Technology, The Royal Society of Chemistry, UK 1997.

[2] A. Varshneya, Fundamentals of Inorganic Glasses, Academic Press, New York 1994.

[3] T. Yano, N. Kunimine, S. Shibata, M. Yamane, J. Non-Cryst. Solids 321, 137 (2003).

[4] J. Lorösch, M. Couzi, J. Pelous, R. Vacher, A. Levasseur, J. Non-Cryst. Solids 69, 1 (1984).

[5] M. Kodama, J. Mater. Sci. 26, 4048 (1991).

[6] Z. Zhang, K. Hirao, N. Soga, J. Non-Cryst. Solids 135, 62 (1991).

[7] S. Tanabe, S. Todoroki, K. Hirao, N. Soga, J. Non-Cryst. Solids 122, 59 (1990).

[8] H. Doweidar, J. Phys. Chem. Solids 53, 807 (1992).

[9] H. Miyoshi, D. Chen, H. Masui, T. Yazawa, T. Akai, J. Non-Cryst. Solids 345\&346, 99 (2004).

[10] I. Kityk, A. Majchrowski, J. Zmija, Z. Mierczyk, K. Nouneh, Crystal Growth Design 6, 2779 (2006).

[11] A. Majchrowski, I. Kityk, E. Mandowska, A. Mandowski, J. Ebothé, T. Lukasiewicz, J. Appl. Phys. 100, 053101 (2006).

[12] B. Das, R. Ambika, Chem. Phys. Lett. 370, 670 (2003). 
[13] N. Syam Prasad, K. Varma, Mater. Sci. Eng. B 90, 246 (2002).

[14] Y. Cheng, H. Xiao, W. Guo, W. Guo, Ceram. Int. 33, 1341 (2007).

[15] R. Iordanova, V. Dimitrov, Y. Dimitriev, D. Klissurski, J. Non-Cryst. Solids 180, 58 (1994).

[16] G. Sharma, K.S. Thind, Monika, H. Singh, Manupriya, L. Gerward, Phys. Status Solidi A 204, 591 (2007).

[17] I. Oprea, H. Hesse, K. Betzler, Phys. Status Solidi B 242, R109 (2005).

[18] Y. Saddeek, J. Alloys Comp. 476, 14 (2009).

[19] Y. Saddeek, A. Abousehly, S. Hussien, J. Phys. D, Appl. Phys. 40, 4674 (2007).

[20] Y. Saddeek, M.S. Gaafar, Mater. Chem. Phys. 115, 280 (2009)

[21] B. Bridge, N. Patel, D. Waters, Phys. Status Solidi A 77, 655 (1983)
[22] B. Bridge, A. Higazy, Phys. Chem. Glasses 27, 1 (1986).

[23] A.F. Wells, Structural Inorganic Chemistry, 4th ed., Clarendon Press, Oxford 1975.

[24] N. Mohan, G. Baskaran, N. Veeraiah, Phys. Status Solidi A 203, 2083 (2006).

[25] D. Lide, CRC Handbook of Chemistry and Physics, 84th ed., CRC Press, Boca Raton, Fl 2004.

[26] Y. Saddeek, Physica B 344, 163 (2004).

[27] V. Rajendran, N. Palanivelu, B.K. Chaudhuri, K. Goswami, J. Non-Cryst. Solids 320, 195 (2003).

[28] Y. Saddeek, Physica B 363, 19 (2005).

[29] M. Jiang, L. Dai, Phys. Rev. B 76, 054204 (2007). 